\title{
INCLUSÃO E DIVERSIDADE NA ADMINISTRAÇÃO: MANIFESTA PARA O FUTURO-PRESENTE
}

\author{
Inclusion and diversity in Management: A manifesta for the future-now \\ Inclusión y diversidad en la Administración: Manifiesta para el futuro-presente
}

Juliana Cristina Teixeira1 | julianacteixeira@yahoo.com.br | ORCID: 0000-0001-5186-3234

Josiane Silva de Oliveira2,3 | oliveira.josianesilva@gmail.com | ORCID: 0000-0002-7085-8921

Ana Diniz ${ }^{4}$ | anaprd@insper.edu.br | ORCID: 0000-0002-9187-3696

Mariana Mazzini Marcondes5 | mariana.mazzini.m@gmail.com | ORCID: 0000-0003-0701-6630

${ }^{1}$ Universidade Federal do Espírito Santo, Departamento e Programa de Pós-Graduação em Administração, Núcleo de Estudos Afro-Brasileiros, Vitória, ES, Brasil

2 Universidade Estadual de Maringá. Departamento e Programa de Pós-graduação em Administração, Núcleo de Estudos Interdisciplinares Afrobrasileiros, Maringá, PR, Brasil

3 Universidade Federal de Goiás. Programa de Pós-graduação em Administração, Goiânia, GO, Brasil.

${ }^{4}$ Insper Instituto de Ensino e Pesquisa, São Paulo, SP, Brasil

5 Universidade Federal do Rio Grande do Norte, Departamento de Administração Pública e Gestão Social do Centro de Ciências Sociais Aplicadas, Natal, Rio Grande do Norte, Brasil

\section{RESUMO}

No marco temporal de aniversário da RAE-Revista de Administração de Empresas, o objetivo deste artigo, que pode ser interpretado como uma manifesta, é discutir o papel das revistas acadêmicas em Administração para a inclusão e a diversidade. Entendemos que nos manifestarmos sobre o papel das revistas em processos de reparação histórica de desigualdades é também sobre nos reconectar com a crítica ao conceito e à prática da diversidade presentes no campo da Administração, e é justamente por esse debate que iniciamos a construção do nosso argumento, logo após a introdução. Ancorando-nos em referenciais teóricos sistematizados a partir das práticas e dos conhecimentos dos movimentos sociais (interseccionalidade, transversalidade e decolonialidade), apresentamos nossa manifesta por uma agenda de transformações para as práticas sobre diversidade no campo.

PALAVRAS-CHAVE | Diversidade, desigualdades, interseccionalidade, transversalidade, decolonialidade.

\section{ABSTRACT}

In marking the anniversary of RAE-Revista de Administração de Empresas, the purpose of this article, which can be interpreted as a manifesta, is to discuss the role of academic journals in Administration with regard to inclusion and diversity. We understand that when we talk about the role of journals in processes for repairing historical inequalities we are also talking about reconnecting with criticisms of the concept and practice of diversity that are found in the field of Administration, and it is precisely with this debate that we begin to build our argument right after the introduction. Based on theoretical references that are systematized by the practices and knowledge of social movements (intersectionality, mainstreaming and "decoloniality"), we present our manifesta for an agenda of transformations for practices relating to diversity in the field.

KEYWORDS I Diversity, inequality, intersectionality, mainstreaming, decoloniality.

\section{RESUMEN}

En el marco temporal del aniversario de la RAE-Revista de Administração de Empresas, el objetivo de este artículo, que puede interpretarse como un manifiesta, es discutir el papel de las revistas académicas de Administración para la inclusión y la diversidad. Entendemos que manifestarnos sobre el papel de las revistas en procesos de reparación histórica de desigualdades es también reconectarnos con la crítica al concepto y a la práctica de la diversidad presente en el campo de la Administración, y es precisamente a través de ese debate que comenzamos la construcción de nuestro argumento, inmediatamente después de la introducción. Respaldándonos en marcos referenciales teóricos sistematizados a partir de las prácticas y de los conocimientos de los movimientos sociales (interseccionalidad, transversalidad y decolonialidad), presentamos nuestro manifiesta por una agenda de transformaciones para las prácticas sobre diversidad en el campo.

PALABRAS CLAVE I Diversidad, desigualdades, interseccionalidad, transversalidad, decolonialidad. 


\section{INTRODUÇÃO}

Recorrendo ao pretuguês[1] (Gonzalez, 1984), "que tal cês começarem esse texto fazendo um exercício reflexivo?”. Vamos a uma situação hipotética de consideração das barreiras para se promover inclusão e diversidade na Administração. Uma das etapas desse processo envolve a escrita e divulgação de trabalhos sobre a temática, a fim de construir uma agenda de debates no campo. Imagine que você é um/a pesquisador/a da área de Estudos Organizacionais e proporá uma chamada especial sobre inclusão e diversidade em uma revista acadêmica no nível máximo de classificação do Qualis Capes:

1. Quem você chamaria para compor o grupo proponente?

2. Imagine que esse grupo precisa ser composto por $50 \%$ de homens e $50 \%$ de mulheres. A composição inicial atenderia? Como você adequaria? Como comunicaria a quem precisasse se retirar? Como faria novos convites para atender a essa distribuição?

3. Agora, o grupo também precisa ser composto por $50 \%$ de pessoas não brancas e $50 \%$ brancas. 0 grupo era assim? Se não, seria fácil adequá-lo?

4. Além dos requisitos acima, o grupo precisa contemplar uma distribuição igualitária entre pessoas heterossexuais e não heterossexuais. 0 que você faria?

5. E se, além do que foi dito, o grupo precisasse ser composto também por pessoas cis e por travestis, transgêneros ou transexuais? Você conseguiria montar esse grupo na sua área de pesquisa?

6. E se precisasse, também, contar com pelo menos uma representante de grupos indígenas ou comunidades quilombolas? E aí?

7. E se, por fim, fosse necessário incluir pessoas de regiões diversas, não sendo centrado no eixo Sudeste e Sul do Brasil? O grupo era assim?

8. Ainda não acabou o exercício, só mais um pouco: percorra novamente todo esse itinerário e imagine que esse grupo deve ser composto por pesquisadoras e pesquisadores de outras áreas da Administração, como Finanças, Logística ou outras. Como seria?

“Conta pra gente, cê conseguiu compor mentalmente os grupos?" Nós imaginamos que não. Porque, mesmo nós, propositoras deste artigo, que temos trajetórias políticas e acadêmicas nas temáticas mencionadas, temos dificuldade de diversificar nosso rolê. Somos quatro mulheres cis heterossexuais, duas mulheres negras e duas brancas, todas nascidas no Sudeste e Sul, embora duas atuem em instituições fora desse eixo.

Nossa trajetória contempla a coordenação conjunta de tema de interesse sobre desigualdades e diferenças na divisão de Estudos Organizacionais da Associação Nacional de Pós Graduação e Pesquisa em Administração (ANPAD), e atuação acadêmica e profissional nessa área e/ou no campo de Públicas. Nossas áreas são marcadas

[1] Pretuguês é o título proposto por Lélia Gonzalez (1984) ao português falado no Brasil, marcadamente influenciado pela fala das pessoas negras que vieram em diáspora forçada do continente africano para o País, para serem escravizadas. Essa influência explica modos de fala que transformam você em cê, que cortam o som dos erres dos verbos na forma infinitiva (escrevê, fazê), e que trocam sons de $L$ por $R$ (Creusa). Lélia destaca que essas marcas foram ignoradas pelo racismo, ao integrarem uma ideia de que as pessoas negras seriam intelectualmente inferiores e, por esse motivo, mais desconectadas com a norma culta da língua portuguesa. 
por pluralidade epistemológica, teórica e metodológica. No entanto, essa pluralidade é perdida quando o assunto é a adequada representatividade da diversidade que compõe nosso país no corpo docente e discente do campo. Neste aniversário da RAE-Revista de Administração de Empresas, o objetivo inicial deste texto, que pode também ser recebido como uma manifesta, seria discutir o papel das revistas acadêmicas em Administração na inclusão e diversidade. Seria algo como pensarmos uma agenda para o futuro. A estrutura do nosso argumento ultrapassa, contudo, a esfera das revistas acadêmicas, embora a elas também se refira.

Propomos, assim, a ampliação da discussão para o campo da Administração. Essa proposta encontra base: (1) nas nossas experiências na articulação de debates sobre as temáticas no campo, que compreende um fazer político-acadêmico também de bastidores de suas práticas institucionalizadas; (2) no aporte teórico conectado com as experiências educativas dos movimentos sociais: interseccionalidade, decolonialidade e transversalidade; e (3) no caráter intrínseco do debate acadêmico com a transformação social de caráter mais estrutural.

Nesse sentido, entendemos que nos manifestar sobre o papel das revistas em processos de reparação histórica de desigualdades é também sobre nos reconectar com a crítica ao conceito e à prática da diversidade preponderante no campo, e é justamente por esse debate que iniciamos a construção do nosso argumento, logo após esta introdução. Em seguida, trazemos a discussão sobre a fundamentação teórica da nossa agenda para, na quarta parte, apresentarmos nossa manifesta por uma agenda de transformação na Administração.

Adiantamos que, em termos práticos, entendemos que chamar uma pessoa negra e uma mulher para um painel sobre diversidade, por exemplo, não configura uma prática de diversidade. Atuamos em contextos em que ações superficiais têm colaborado para uma cooptação despolitizada da pauta. Quando nos deslocamos dessa visão acrítica para outra, crítica e transformativa sobre as desigualdades, reconhecemos que é urgente agir de maneira aprofundada nas raízes do campo. Assim, defendemos que ações mais superficiais são apenas passos, pois as insurgências em nossa área dependem de uma quebra com o padrão de momentos episódicos para transformações estruturais rumo à diversidade. Dessa maneira, nosso argumento desenvolve entendimentos sobre as implicações desse debate para as diferentes áreas, conectando com o campo da Administração como um todo.

\section{DIVERSIDADE NA ADMINISTRAÇÃO}

O debate sobre diversidade na Administração ganhou força a partir dos anos 1990 nos Estados Unidos (Cox \& Blake, 1991; Fleury, 2000). No entanto, iniciativas mais estruturadas para lidar com o tema remontam aos anos 1960, quando foram desenvolvidas as primeiras políticas públicas afirmativas no país, em resposta a demandas do Movimento pelos Direitos Civis (Moehlecke, 2002; Pate, 2000). Os fundamentos legais dessas iniciativas remetem, por sua vez, ao contexto internacional mais amplo, sendo recomendadas em tratados e convenções das Nações Unidas, além de legislações nacionais (Hodges-Aeberhard, 1999), como é o caso brasileiro (Bandeira, 2005; Jaccoud \& Beghin, 2002).

Desde 1960, as ações afirmativas vêm se difundindo pelo mundo, mas não sem contestações (Moehlecke, 2002; Pate, 2000). Questionamentos enfatizam que esse tipo de política seria uma forma de "discriminação reversa", um meio de desvalorizar os feitos dos grupos beneficiários ou, até mesmo, de reforçar uma espécie de "tribalismo" entre grupos (Piovesan, 2008; Scott, 2005). Tais críticas embasaram uma onda de processos judiciais contra as políticas afirmativas estadunidenses nos anos 1990, movidos principalmente por trabalhadores/as e estudantes que se sentiam injustiçados/as em processos seletivos e de ascensão profissional (Hodges-Aeberhard, 1999). 
É nesse contexto que surge uma alternativa gerencial para lidar com a diversidade no trabalho (Alves \& Galeão-Silva, 2004). A gestão da diversidade constitui um conjunto de práticas que visam tanto aumentar a participação de grupos excluídos nas organizações quanto adicionar valor às empresas (Fleury, 2000). Nesse processo, diversidade é frequentemente entendida como um mix de pessoas com diferentes atributos individuais e grupais (Alves \& Galeão-Silva, 2004). Isso incluiria não só diferenças historicamente lidas como fontes de desigualdades, como gênero, sexualidade, raça, etnia e classe, mas as múltiplas diferenças entre as pessoas (Hanashiro \& Carvalho, 2005). De acordo com essa perspectiva, as identidades e habilidades resultantes dessa pluralidade devem ser manejadas como recursos estratégicos para aumentar o desempenho organizacional (Thomas, 1990).

A defesa da gestão da diversidade baseia-se em dois pontos principais (Alves \& Galeão-Silva, 2004). Primeiramente, essa proposta permitiria a construção de programas mais justos, baseados na "meritocracia". 0 alinhamento com a lógica empresarial tornaria essas iniciativas também mais "orgânicas" e efetivas na criação de um ambiente organizacional favorável à diferença (Hanashiro \& Carvalho, 2005). Em segundo lugar, a gestão da diversidade permitiria atenuar as desvantagens e ampliar as vantagens de equipes diversas (Conceição \& Spink, 2013; Prügl, 2011), tornando-se ainda mais crucial em um contexto globalizado e competitivo no qual a homogeneidade entre trabalhadores/as não seria mais uma opção para as empresas. Assiste-se, assim, a uma virada nos discursos sobre diversidade e gestão: não se tratava mais de uma questão de justiça social, mas de sobrevivência empresarial (Thomas, 1990).

A gestão da diversidade foi incorporada no Brasil nos anos 1990, trazida principalmente por subsidiárias de multinacionais norte-americanas (Fleury, 2000; Hanashiro \& Carvalho, 2005). No entanto, a proposta nunca decolou em solo nacional (Conceição \& Spink, 2013; Santos, Rodrigues, Dutra, \& Costa, 2008). Levantamento desenvolvido pelo Instituto Ethos (2016) mostra que, entre as 500 maiores empresas no País, apenas $28 \%$ desenvolvem iniciativas para incentivar a participação de mulheres, $12 \%$ para pessoas negras e $9 \%$ para aquelas com acima de 45 anos, sendo a maior parte dessas ações pontual. Mesmo os programas para pessoas com deficiência não são amplamente difundidos, a despeito dos dispositivos legais existentes para estimular a inserção do grupo. Estudos (e.g. Diniz, Carrieri, Gandra, \& Bicalho, 2013; Saraiva \& Irigaray, 2009) apontam, ainda, para a inefetividade dos programas implementados, dados a não incorporação de uma reflexão ético-moral que dê sustentação às práticas desenvolvidas, o baixo comprometimento gerencial e o preconceito arraigado nas dinâmicas organizacionais.

Barreiras também são observadas no avanço da pesquisa no tema. 0 artigo de Maria Tereza Leme Fleury (2000) na $R A E$, que inaugurou o debate sobre diversidade no campo, foi seguido por um aumento substantivo de publicações, muitas delas debatendo os limites da prática e as possibilidades de melhoria. Esses trabalhos têm sido amplificados por estudos nem sempre amparados na chave teórica da diversidade, mas que trazem reflexões sobre as desigualdades de gênero, sexualidade, raça, etnia, geracionais, regionais e as enfrentadas por pessoas com deficiência, entre outras. Movimento semelhante pode ser visto em congressos da área, com abertura de temas dedicados à diversidade e às diferenças, como são os casos do EnANPAD e de encontros de área, como o EnEO, EnAPG e EnGPR. Esse debate fundamental para a Administração segue, contudo, uma frente de resistência, marginalizada pela hegemonia do campo e "guetizada" em áreas específicas, como os Estudos Organizacionais e a Administração Pública.

Limites podem ser observados, ainda, na promoção de reflexão-ação mais contundente para transformar as escolas e o ambiente acadêmico da Administração. Corpos docentes e discentes seguem, em sua maioria, masculinos, brancos e privilegiados. Análise da base de dados de 2019-2020 da Coordenação de Aperfeiçoamento de Pessoal de Nível Superior (CAPES, 2021) mostra que apenas 33\% dos professores em programas de pós-graduação 
na área são mulheres. A participação feminina é ainda menor entre programas com conceito 5 e 6 . A disparidade regional também é evidente, com concentração de $45 \%$ dos programas na região Sudeste e $25 \%$ no Sul. Dados que nos permitam refletir sobre as disparidades raciais, étnicas, econômicas e relacionadas às identidades sexuais e de gênero não são sequer coletados, revelando a distância a que estamos de uma política articulada que favoreça a inclusão de pessoas negras, pobres, trans e não heterossexuais no corpo docente da pós no Brasil.

Um olhar para o corpo discente indica, contudo, possibilidades de mudança. Mulheres compõem $46 \%$ dos/ as estudantes em programas de pós avaliados nas áreas de Administração Pública e de Empresas, Ciências Contábeis e Turismo. Mais participação feminina é observada nos cursos acadêmicos, somando $48 \%$ perante $43 \%$ de alunas nos mestrados e doutorados profissionais. Como no caso das docentes, mulheres estão menos presentes entre estudantes de programas com conceito 5 e 6 e em programas de universidades privadas. A maior participação feminina é encabeçada por mulheres jovens, que já ultrapassam os 50\% entre os/as estudantes com até 29 anos (CAPES, 2021). Mulheres somam também 54,9\% de estudantes nos cursos de graduação da área de Negócios, Administração e Direito. As pessoas negras seguem, contudo, sub-representadas na graduação de maneira geral, a despeito dos relevantes avanços promovidos pelas políticas de cotas (Semesp, 2020).

Os limites para avanço da diversidade remetem à forma como o debate das diferenças e desigualdades tem sido hegemonicamente incorporado na Administração. Em trabalho sobre executivos negros, Jaime (2016) discute como a gestão da diversidade foi adotada como uma linguagem para mediar o conflito entre organizações, agentes governamentais e sociedade civil. Essa tradução levou, contudo, a uma despolitização de pautas históricas de movimentos sociais. Como evidenciam Alves e Galeão-Silva (2004), as propostas gerenciais deslocam a questão das diferenças de um conflito político, incontrolável e societário para uma variável apolítica e funcional, submetendo a demanda de inclusão à lógica de mercado, lógica essa não só masculina, mas branca e colonial (Gonzalez, 1984).

Na seção seguinte, articulamos uma abordagem alternativa que busca repolitizar e potencializar a reflexão-ação rumo à diversidade e inclusão no campo.

\section{SOBRE INTERSECCIONALIDADE, DECOLONIALIDADE E TRANSVERSALIDADE}

Para repolitizarmos as teorias e práticas da Administração em relação à inclusão e diversidade, é necessário ultrapassar saídas individuais para alcançar as raízes dessa problemática. Isso requer compreender as dimensões institucionais e estruturais que conformam o campo como atravessadas pelas relações históricas e políticas que dão materialidade à realidade social como um todo (Ramos, 1981). Por isso, é possível construir um paralelo com as discussões teórico-políticas acerca do racismo.

0 racismo não é um conjunto de fenômenos episódicos, usando expressão de Joel Rufino dos Santos (1999) para se contrapor ao seu entendimento como uma "problemática de 'minoria”" (p. 120). Trata-se um sistema de opressão baseado na noção de raça, entendida como uma ideologia (Munanga, 2015), que atua como organizadora psíquica dos sujeitos e grupos (Santos, 1983). Baseado em uma ideologia entrecortada pelos efeitos do capitalismo e sexismo (Gonzalez, 1984), o racismo promove meios de estruturação da sociedade em seus diversos níveis, inclusive nos institucionais.

No entanto, mimetismos na formação das organizações modernas promoveram, por exemplo, uma aparência de que "negro é raça", lembrando a crítica de Santos (1999) a como se leem as pessoas negras no Brasil. O autor destaca que "negro" é um lugar social mantido a partir de uma estrutura desigual e excludente (Santos, 
1999), e que deve também ser entendido como relacional ao lugar da branquitude que se reverbera como padrão de poder nessas organizações (Gouvêa \& Oliveira, 2020).

Fazendo um paralelo com a teoria das organizações, Peci (2006) chama a atenção para a superestimação do mimetismo organizacional como fenômeno de entendimento da formação e regulação das instituições nas teorias institucionais, que são clássicas no campo da Administração. Voltando à discussão racial, o racismo também tende a ser tratado como mero mimetismo individual ou grupal, e não como algo estrutural sustentado por relações históricas de poder em nossa sociedade (Almeida, 2018).

Partindo dessas reflexões, entendemos que a construção de um campo comprometido com o enfrentamento às desigualdades e a promoção da inclusão e diversidade passa por forjarmos instrumentos que nos permitam operar nessa complexidade estrutural. Nesta manifesta, dialogamos com conhecimentos e práticas transformativas desenvolvidas pelos movimentos sociais, especialmente os feministas (e) negros, para propormos uma agenda transformadora para a Administração. Para tanto, nos amparamos em três conceitos (que são também três práticas) para delinear um caminho de reflexão-ação sobre propostas concretas para o campo. São eles: a interseccionalidade, a decolonialidade e a transversalidade.

A interseccionalidade foi sistematizada por Kimberlé Crenshaw em 1989 (Teixeira, 2020). A história da interseccionalidade, contudo, atravessa a ação das mulheres negras para politizar as relações de raça, gênero e classe de maneira articulada. Durante as convenções pelos direitos das mulheres nos Estados Unidos em 1851, Sojourner Truth, uma mulher negra escravizada, questionou: "Ninguém nunca me ajudou a subir nas carruagens... e nem pular poças de lama... E eu não sou uma mulher?" (Truth, 1851). Por meio desse questionamento, ela apontava que a construção de um feminino universal era, na verdade, a generalização das experiências de mulheres brancas de classes médias e altas.

As contribuições de intelectuais negras estadunidenses, como Angela Davis (2016), Audre Lorde (1984) e bell hooks (2000), foram fundamentais para o desenvolvimento das teorias e práticas interseccionais ao longo do tempo. No entanto, é fundamental destacar também as contribuições do Sul Global, a exemplo dos aportes desenvolvidos pelas brasileiras Lélia Gonzalez (1984), Beatriz Nascimento (1990) e Sueli Carneiro (2003), e, inclusive, refletir acerca da não incorporação dessas autoras quando o conceito é sistematizado.

Com base em Crenshaw (2002), compreendemos a interseccionalidade como a articulação de eixos de poder e de discriminação que, de modo estrutural, produzem opressões. É o caso das relações sociais de raça, etnia, gênero, sexualidade e classe. Assim, é necessário pensar e agir de maneira articulada e integrada se quisermos produzir igualdades e inclusão, com respeito às diversidades.

A decolonialidade, por sua vez, pode ser compreendida como um projeto que, por um lado, sistematiza uma crítica à colonialidade (Quijano, 2005) e, de outro, apresenta uma alternativa a ela (Abdalla \& Faria, 2017; Alcadipani \& Rosa, 2010; Amaral \& Naves, 2020; Rezende, Mafra, \& Pereira, 2018; Silva, André, Wanderley, \& Bauer, 2020).

A colonialidade remete ao projeto de modernidade colonial que separa e hierarquiza raças, povos, gêneros e sexualidades, culturas, línguas e saberes, como forma de estabelecer e legitimar a hegemonia eurocêntrica. Ela vai além do processo histórico de colonização da América, da África e da Ásia por países europeus, integrando-se (e estruturando) o modo de produção capitalista contemporâneo. Seus efeitos não se limitam à organização geopolítica da economia, por meio da divisão internacional do trabalho (centro/periferia), mas abrangem a construção de formas hegemônicas de racionalidades e epistemes, incluindo a linguagem (a exemplo do uso do inglês como idioma universal). Trata-se de uma monocultura do saber (Santos, Araújo, \& Baumgarten, 2016). Já a decolonidade é uma proposta teórica e prática de reposicionar politicamente os sujeitos e povos marginalizados como origem e fonte de saberes e práticas (Lugones, 2014). 
A construção de mediações entre decolonialidade e interseccionalidade oferece-nos bases robustas para a reflexão. Decolonizar é, em grande medida, reconhecer a intersecção sobre formas de desigualdades e construir caminhos para que os sujeitos e comunidades que vivem à margem estejam no centro de um projeto emancipatório. A interseccionalidade, por sua vez, torna-se mais potente à medida que se descoloniza.

Finalmente, situamos a transversalidade de gênero. Entendida como uma tradução-ressignificação do gender mainstreaming (Farah, 2004; Papa, 2012; Reinach, 2013), a transversalidade remete aos esforços de movimentos feministas em forjar estratégias para comprometer a ação pública com a igualdade de gênero. Essa estratégia difundiu-se a partir da IV Conferência Mundial da Mulher, ocorrida em Beijing, em 1995, dando suporte ao desenvolvimento de políticas públicas em diversos países (Guzmán, 2001; Walby, 2005). No Brasil, fundamentou tanto as iniciativas de institucionalização de políticas para as mulheres (Bandeira, 2005; Marcondes, 2019; Papa, 2012) quanto para a igualdade racial, juventude e direitos humanos (Marcondes, Sandim, \& Diniz, 2018; Reinach, 2013), especialmente durante os governos federais petistas.

Partindo de literaturas feministas sobre o tema (Bandeira, 2005; Farah, 2004; Marcondes, 2019), entendemos a transversalidade como um processo que busca reorientar a reflexão-ação por meio da introdução de perspectivas (de gênero, raça, etnia etc.) que a comprometa com a promoção da igualdade e da inclusão de sujeitos historicamente discriminados. Trata-se de uma dinâmica essencialmente conflitiva, contraditória, e seus resultados são permeados por nuances e até mesmo descontinuidades.

A transversalidade envolve uma disputa em torno das ideologias e discursos que estruturam os problemas e as alternativas de ação para responder a eles. A reorientação pela perspectiva de igualdade de gênero, por exemplo, pressupõe reconhecer que, historicamente, pensamento e ação estiveram comprometidos com a produção e legitimação da desigualdade de gênero. Além disso, a transversalidade deve abranger a viabilização de condições materiais e institucionais para que sua gestão se efetive. É o caso da criação de organismos de coordenação e da elaboração de planos e indicadores, entre outros instrumentos.

Assim, a transversalidade busca reorientar a reflexão-ação em um sentido diverso do que vem sendo historicamente percorrido, trazendo perspectivas marginalizadas para o centro. Nesse processo, ela pode ancorar-se na interseccionalidade e decolonialidade para potencializar seus efeitos. E, ainda que venha sendo utilizada principalmente em âmbito estatal, ela nos oferece instrumentos para disputar e transformar outros espaços, como o próprio campo da Administração.

Com base nesses referenciais, introduzimos as propostas a seguir.

\section{POR UMA AGENDA DE TRANSFORMAÇÃO}

Para ampliarmos temáticas e participação de grupos historicamente colocados à margem do campo, é necessário alterarmos a própria lógica do campo que opera para colocar esses grupos na condição de objetos, e não de sujeitas e sujeitos no mundo. Essa agenda de transformação deve contemplar diversas frentes.

Em um primeiro momento, é preciso considerar que quem cria a ideia do que sabemos sobre diversidade é quem ocupa o local de norma. Então, em uma perspectiva interseccional, é preciso desnaturalizar os elementos que nos foram colocados como norma e que decorrem da forma de produção socioeconômica e organização da vida, em termos de gênero, sexualidade, raça, etnia, classe, deficiência, entre outros. Isso deve ser colocado em debate na medida em que as próprias lógicas de constituição das instituições possam ser colocadas em ques- 
tionamento e evidenciadas como pontos de vista singulares, e não universais. Se, como nos diz Fanon (2020), o branco criou o negro a partir de suas fantasias, Said (2007) nos alerta nesse mesmo entendimento na relação do Ocidente com o Oriente, e Lugones (2014) o faz em relação aos debates de gênero e colonialismo. Portanto, é preciso que o que foi denominado como diversidade deixe a condição de reafirmação da norma e passe a se constituir a partir de seus próprios processos.

Isso implica uma segunda frente dessa agenda, que diz respeito às normas de composição das instituições que articulam esses debates, que podem ser pensadas, de maneira crítica e propositiva, em uma perspectiva interseccional. Isso é importante, pois, sem as condições materiais necessárias para que essa agenda sobre diversidade se efetive, ela ocupará, novamente, o lugar de uma proposta de futuro que nunca chegará, que permanece à margem. Aqui, apontamos para o questionamento sobre distribuição de recursos, inclusive financeiros, ocupação de espaços em corpos editoriais de revistas, de associações de classe, de reconhecimento de tecnologias e processos de gestão que rompam com a lógica de preservação de processos que são, de maneira explícita ou não, excludentes.

Uma das formas como essas tecnologias se manifestam é por meio da linguagem (Gonzalez, 1984). A integração internacional de nossos processos de trabalho é importante, mas isso não significa, necessariamente, a hegemonia da língua inglesa. 0 espanhol, por exemplo, permanece subjugado no contexto de gestão editorial. E essa crítica vale inclusive em relação à adoção do inglês como língua oficial para se ministrarem aulas na área de Administração. 0 uso do inglês na Administração no Brasil, um país integrante da América Latina e do Sul Global, aponta para quem esses espaços são destinados, e como eles se reproduzem impedindo a diversidade. Outro exemplo desse impedimento, dentro mesmo do contexto de nacionalização da pesquisa, é o silenciamento de revistas brasileiras quanto à promoção de acessibilidade de seus conteúdos à língua brasileira de sinais, que é outra língua oficial nossa. Adotar uma agenda de pesquisa que fale sobre diversidade, enquanto, no cotidiano, essa diversidade se torna suprimida, é colocar essas discussões como objeto, e não como projeto a ser efetivado em uma área científica.

É preciso considerar que não é somente a presença de pessoas trans, negras, mulheres, pessoas com deficiência ou de países em desenvolvimento, por exemplo, que tornará uma instituição efetivamente engajada nessa pauta. A questão é a efetividade de uma outra lógica de operação para a superação das desigualdades, o que perpassa a ocupação efetiva desses espaços (ou a supressão deles) por esses grupos sociais. Ainda, essa ocupação não pode ser superficialmente tratada como cooptação da diferença, o que se observa tanto nas dinâmicas de sobrevivência interna do campo científico quanto nas agendas de internacionalização nesse campo. Nesse sentido, é preciso discutir em que medida a visão de internacionalização pode se configurar mais como cooptação da diferença e hegemonização pelo Norte Global. Podemos (e devemos) nos questionar: Por que a internacionalização não é pelo Sul Global ou por outros idiomas, como o espanhol?

A terceira frente proposta para uma agenda sobre diversidade refere-se aos temas de pesquisas. É preciso considerar que a temática sobre desigualdades e diversidades é transversal e constituinte no campo da Administração. Existem implicações financeiras, mas também de formação de cadeias de suprimentos e de logística, de nossos modos de produção e de consumo, de tecnologias de informação, que estruturam e organizam todos esses debates e que podem apresentar outras reflexões e propostas de intervenção para além das políticas públicas, de gestão de pessoas ou de organização. Nesses termos, para constituir um processo de transversalidade, entendido como uma reorientação do curso das teorias e práticas da Administração em prol da igualdade e inclusão, é necessário criar condições materiais e institucionais para que essa disputa possa ser reposicionada, deslocando-se da margem para o centro. 
Nesse mesmo sentido, é importante a criação de mecanismos para a gestão dessa transversalidade, como planos de ação, com metas e indicadores, assim como organismos que permitam gerir esse processo, que possam ser adotados nas mais diversas organizações acadêmicas (universidades, associações de pesquisas, conselhos editoriais), com participação social.

Indo além, é necessário avançar em uma agenda de temáticas que contemple um debate de desconstrução de silenciamentos, abarcando também "quem inventou" o que se denomina diversidade. Nas discussões sobre gênero, é preciso compreender diferentes masculinidades e suas interseções com raça, classe, sexualidade, nacionalidades ou regionalidades, em uma perspectiva interseccional. Nem todas as masculinidades são hegemônicas (e.g.). Da mesma forma, nem todas as heterossexualidades são hegemônicas, uma vez que há pessoas travestis, transgêneras e transexuais que são heterossexuais. Assim, é possível compreender que o que se nomeou diversidade também está relacionado a um entendimento específico sobre a hegemonia masculina na área: representada por homens cis brancos heterossexuais, de classe média e residentes nas regiões Sudeste e Sul do País.

Por outro lado, apesar de o Brasil ser um dos líderes mundiais em assassinato de pessoas travestis, transgêneras e transexuais, pouco se discute como as práticas de gestão reproduzem essa lógica no País, ou mesmo a possibilidade de essas práticas produzirem outras realidades para esse grupo social em nosso cotidiano. Paniza (2020) argumenta que uma possibilidade para a área seja a de questionar também "a adoção de siglas (como a LGBT) como conceitos universalmente representativos e unificados" (p. 13). A própria ideia de construção conjunta de pautas com os movimentos sociais abarcaria uma agenda comprometida com a reversão de um quadro em que gays são encontrados como sujeitos de pesquisa na área, mas os que representam as demais letras da sigla são silenciados.

Em termos de relações raciais, apesar de os debates sobre branquitudes terem avançado teoricamente nos campos da Sociologia, História, Antropologia ou Psicologia, na área de Administração ainda há muito que se avançar. Se as temáticas vinculadas às populações negras, muito em decorrência das provocações do campo do feminismo negro, têm possibilitado avançar nesses debates, discussões sobre indígenas e outras racializações, a exemplo dos conflitos em territórios árabes e asiáticos, ainda são pouco apresentadas em nosso campo. Esse cenário sugere um campo de oportunidades, inclusive, para se repensarem os limites do que têm se tornado os movimentos de propostas decoloniais do campo.

Pouco se discute, por exemplo, sobre os efeitos do envelhecimento na Administração (Cepellos, Silva, \& Tonelli, 2019). E, mais ainda, o que é envelhecer em um contexto em que o tempo é considerado uma variável que deve ser controlada. Por fim, é preciso considerar que parte significativa dos estudos sobre diversidade ocorre no contexto urbano. Trabalhadoras e trabalhadores rurais, processos organizativos no/do campo e as diversas ruralidades ainda são pouco estudados para a compreensão de suas diversidades, assim como as nossas relações com a natureza, como nos colocam os debates sobre o Antropoceno, contribuem e devem ser discutidas em toda a sua amplitude na área de Administração.

\section{NOTA DAS AUTORAS}

Mantivemos os prenomes das autoras e autores por extenso para dar visibilidade à produção feminina. 


\section{REFERÊNCIAS}

Abdalla, Marcio M., \& Faria, Alex. (2017). Em defesa da opção decolonial em administração/gestão. Cadernos EBAPE.BR, 15(4), 914-929. doi: 10.1590/1679-395155249

Alcadipani, Rafael, \& Rosa, Alexandre R. (2010). O pesquisador como o outro: Uma leitura pós-colonial do "Borat" brasileiro. RAE-Revista de Administração de Empresas, 50(4), 371-382. doi: $10.1590 /$ So034-75902010000400003

Almeida, Silvio. (2018). Racismo estrutural. Belo Horizonte, MG: Letramento.

Alves, Mário A., \& Galeão-Silva, Luiz Guilherme. (2004). A crítica da gestão da diversidade nas organizações. RAE-Revista de Administração de Empresas, 44(3), 20-29. doi: 10.1590/ So034-75902004000300003

Amaral, Isabela G., \& Naves, Flávia. (2020). O enfrentamento das opressões de gênero numa universidade pública: 0 papel dos coletivos na ótica do feminismo decolonial. Revista Brasileira de Estudos Organizacionais, 7(1), 151-184. doi: 10.21583/2447-4851.rbeo.2020.v7n1.305

Bandeira, Lourdes M. (2005). Fortalecimento da Secretaria Especial de Políticas para as Mulheres: Avançar na transversalidade da perspectiva de gênero nas políticas públicas. Brasília, DF: Cepal; SPM.

Carneiro, Sueli. (2003). Mulheres em movimento. Estudos Avançados, 17(49), 117-133. doi: 10.1590/So10340142003000300008

Cepellos, Vanessa M., Silva, Gabriela T., \& Tonelli, Maria José. (2019). Envelhecimento: Múltiplas idades na construção da idade profissional. Organizações \& Sociedade, 26(89), 269290. doi: 10.1590/1984-9260894

Conceição, Eliane B. da, \& Spink, Peter K. (2013). Which foot first: Diversity management and affirmative action in Brazilian business. Management International, 17, 25-36. doi: 10.7202/1015809ar

Coordenação de Aperfeiçoamento de Pessoal de Nível Superior. (2021). Conjunto de dados abertos da CAPES. Planilhas em Excel. Recuperado de https://dadosabertos.capes.gov.br/dataset

Cox, Taylor H., \& Blake, Stacy. (1991). Managing cultural diversity: Implications for competitiveness organizational. The Executive (Academy of Management), 5(3), 45-56. doi: 10.5465/ame.1991.4274465

Crenshaw, Kimberlé. (2002). Documento para o encontro de especialistas em aspectos da discriminação racial relativos ao gênero. Revista Estudos Feministas, 10(1), 171-188. doi: 10.1590/s0104-026×2002000100011

Davis, Angela. (2016). Mulheres, raça e classe. São Paulo, SP: Boitempo.

Diniz, Ana Paula R., Carrieri, Alexandre de P., Gandra, Gislaine, \& Bicalho, Renata de A. (2013). Políticas de diversidade nas organizações: As relações de trabalho comentadas por trabalhadores homossexuais. Revista Economia \& Gestão, 13(31), 93-114. doi: 10.5752/P.1984-6606.2013V13n31p93
Fanon, Frantz. (2020). Pele negra, máscaras brancas. São Paulo, SP: UBU.

Farah, Marta F. S. (2004). Gênero e políticas públicas. Revista Estudos Feministas, 12(1), 47-71. doi: 10.1590/S0104026X2004000100004

Fleury, Maria Teresa L. (2000). Gerenciando a diversidade cultural: Experiências de empresas brasileiras. RAE-Revista de Administração de Empresas, 40(3), 18-25. doi: 10.1590/ So034-75902000000300003

Gonzalez, Lélia. (1984) Racismo e sexismo na cultura brasileira. Revista Ciências Sociais Hoje, 223-244.

Gouvêa, Josiane B., \& Oliveira, Josiane S. de. (2020). Por que branquitudes, por que (somente) agora? Caderno de Administração, 28(2), 5-14. doi: 10.4025/cadm.v28i2.57245

Guzmán, Virginia. (2001). La institucionalidad de género en el estado: Nuevas perspectivas de análisis (Serie Mujer y Desarrollo, n. 32).. Santiago, Chile: Cepal.

Hanashiro, Darcy M. M., \& Carvalho, Sueli G. de. (2005). Diversidade cultural: Panorama atual e reflexões para a realidade brasileira. REAd, 11(5), 1-21.

Hodges-Aeberhard, Jane. (1999). Affirmative action in employment: Recent court approaches to a difficult concept. International Labour Review, 138(3), 247-272. doi: 10.1111/j.1564-913X.1999.tboo387.x

Hooks, Bell. (2000). Feminism is for everybody. Cambridge, UK: South End Press.

Instituto Ethos. (2016). Perfil social, racial e de gênero das 500 maiores empresas do Brasil e suas ações afirmativas. Ethos.

Jaccoud, Luciana, \& Beghin, Nathalie. (2002). Desigualdades raciais no Brasil: Um balanço da intervenção governamental. IPEA. Brasília.

Jaime, Pedro. (2016). Executivos negros: Racismo e diversidade no mundo empresarial. São Paulo, SP: Edusp.

Lorde, Audre. (1984). Sister outsider: Essays and speeches. Berkeley, CA Crossing Press.

Lugones, María. (2014). Rumo a um feminismo descolonial. Revista Estudos Feministas, 22(3), 935-952. doi: 10.1590/ S0104-026X2014000300013

Marcondes, Mariana M. (2019). Transversalidade de gênero em políticas de cuidado: Uma análise comparada das políticas de cuidado infantil no Brasil, Argentina e Uruguai durante o giro à esquerda (Tese de doutorado, Escola de Administração de Empresas de São Paulo, Fundação Getulio Vargas, São Paulo, SP).

Marcondes, Mariana M., Sandim, Tatiana L., \& Diniz, Ana Paula R. (2018). Transversalidade e intersetorialidade: Mapeamento do debate conceitual no cenário brasileiro. Administração Pública e Gestão Social, 10(1), 22-33. doi: 10.21118/apgs.v10i1.1527

Moehlecke, Sabrina. (2002). Ação afirmativa: História e debates no Brasil. Cadernos de Pesquisa, 117, 197-217. doi: 10.1590/ S0100-15742002000300011 
Munanga, Kabengele. (2015). Porque o racismo e suas práticas e qual é a responsabilidade social que se espera dos profissionais que lidam com as questões da sociedade. Revista Brasileira de Psicologia, 2 (núm. Esp.), 7-15.

Nascimento, Beatriz. (1990). A mulher negra e o amor. Jornal Maioria Falante, (17).

Paniza, Maurício D. R. (2020). Entre a emergência, a submersão e o silêncio: LGBT como categoria de pesquisa em administração. Cadernos EBAPE.BR, 18(1), 13-27. doi: 10.1590/1679-395173482

Papa, Fernanda de C. (2012). Transversalidade e políticas públicas para mulheres no Brasil: Percursos de uma prépolítica (Dissertação de mestrado, Escola de Administração de Empresas de São Paulo, Fundação Getulio Vargas, São Paulo, SP).

Pate, Kimberley. (2000). Ação afirmativa nos Estados Unidos. In D. G. Delgado, P. Cappelin, \& V. Soares (Eds.), Mulher $e$ trabalho: Experiências de ação afirmativa (pp. 85-110). São Paulo, SP: Boitempo Editorial.

Peci, Alketa. (2006). A nova teoria institucional em estudos organizacionais: Uma abordagem crítica. Cadernos EBAPE.BR, 4(1), 1-12. doi: 10.1590/S1679-39512006000100006

Piovesan, Flavia. (2008). Ações afirmativas no Brasil: Desafios e perspectivas. Revista de Estudos Feministas, 16(3), 887-896. doi: 10.1590/S0104-026X2008000300010

Prügl, Elisabeth. (2011). Diversity management and gender mainstreaming as technologies of government. Politics and Gender, 7(1), 71-89. doi: 10.1017/S1743923X10000565

Quijano, Anibal. (2005). Colonialidade do poder, eurocentrismo e América Latina. Buenos Aires, Argentina: Consejo Latinoamericano de Ciencias Sociales (CLACSO).

Ramos, Alberto G. (1981). A nova ciência das organizações: Uma reconceituação da riqueza das nações. Rio de Janeiro, RJ: FGV.

Reinach, Sophia. (2013). Gestão transversal de políticas públicas no âmbito federal brasileiro: Uma leitura inicial (Dissertação de mestrado, Escola de Administração de Empresas de São Paulo da Fundação Getulio Vargas, São Paulo, SP).

Rezende, Ana F., Mafra, Flávia L. N., \& Pereira, Jussara J. (2018). Black entrepreneurship and ethnic beauty salons: Possibilities for resistance in the social (re)construction of black identity. Organizações \& Sociedade, 25(87), 589-609. doi: 10.1590/1984-9250873

Said, Edward. (2007). Orientalismo: O Oriente como invenção do Ocidente. São Paulo, SP: Companhia das Letras.
Santos, Boaventura de S., Araújo, Sara, \& Baumgarten, Maíra. (2016). As epistemologias do Sul num mundo fora do mapa. Sociologias, 18(43), 14-23. doi: 10.1590/15174522-018004301

Santos, Georgina de C. M., Rodrigues, Ivete, Dutra, Shirley E., \& Costa, Bruna de V. L. da. (2008). Gestão da diversidade: Um estudo sobre as "melhores empresas para você trabalhar". Seminários de Administração, 11, 1-16.

Santos, Joel. R. D. dos. (1999). A inserção do negro e seus dilemas. Parcerias Estratégicas, 4(6), 110-154.

Santos, Neusa de S. (1983). Tornar-se negro: As vicissitudes da identidade do negro brasileiro em ascensão social. Rio de Janeiro, RJ: Edições Graal.

Saraiva, Luiz Alex S., \& Irigaray, Hélio Arthur dos R. (2009). Políticas de diversidade nas organizações: Uma questão de discurso? RAE-Revista de Administração de Empresas, 49(3), 337-348. doi: 10.1590/S0034-75902009000300008

Scott, Joan W. (2005). O enigma da igualdade. Revista de Estudos Feministas, 13(1), 11-30. doi: 10.1590/S0104 026X2005000100002

Semesp. (2020). Mapa do ensino superior no Brasil (10 ed.). São Paulo, SP: Semesp.

Silva, Rosana O., André, Robson G., Wanderley, Sérgio. E. P. V., \& Bauer, Ana P. M. (2020). Josué de Castro e a colonialidade do poder, do ser e do saber: Uma contribuição para a opção decolonial em estudos organizacionais. Sociedade, Contabilidade e Gestão, 15(1), 41-60. doi: 10.21446/scg_ufrj. voio.21599

Teixeira, Juliana. (2020). Interseccionalidade. Observatórios das Desigualdades da Universidade Federal do Rio Grande do Norte (UFRN). Glossário das desigualdades. Recuperado de https://ccsa.ufrn.br/portal/?author=101050

Thomas, Roosevelt R. Jr. (1990). From affirmative action to affirmative diversity. Harvard Business Review, 68(2), 107-117. Recuperado de https://hbr.org/1990/03/from-affirmativeaction-to-affirming-diversity

Truth, Sojourner. (1851). E não sou mulher? Recuperado de https://www.geledes.org.br/e-nao-sou-uma-mulhersojourner-truth/

Walby, Sylvia. (2005). Gender mainstreaming: Productive tensions in theory and practice. Social Politics: International Studies in Gender, State \& Society, 12(3), 321-343. doi: $10.1093 / \mathrm{sp} / \mathrm{jxi018}$

\section{CONTRIBUIÇÃO DAS AUTORAS}

Ana Diniz, Josiane Silva de Oliveira, Juliana Cristina Teixeira e Mariana Mazzini Marcondes trabalharam na conceitualização e abordagem teórica-metodológica. A revisão teórica foi conduzida por Ana Diniz, Josiane Silva de Oliveira, Juliana Cristina Teixeira e Mariana Mazzini Marcondes. A coleta de dados foi coordenada por Ana Diniz, Josiane Silva de Oliveira, Juliana Cristina Teixeira e Mariana Mazzini Marcondes. Participaram da análise de dados Ana Diniz, Josiane Silva de Oliveira, Juliana Cristina Teixeira e Mariana Mazzini Marcondes. Todas as autoras participaram da redação e revisão final do manuscrito. 